\title{
Is Aristolochic Acid Really the Cause of the Balkan Endemic Nephropathy?
}

\author{
Peter Mantle, ${ }^{1}$ Diana Herman, ${ }^{2}$ Calin Tatu ${ }^{3}$ \\ ${ }^{1}$ Centre for Environmental Policy, Imperial College London, London, UK; \\ 2 Department of Pathology, Guy's and St Thomas' NHS Foundation Trust, London, UK; \\ ${ }^{3}$ Department of Biology, University of Medicine and Pharmacy "Victor Babes", Timisoara, Romania.
}

\begin{abstract}
In recent years, aristolochic acid has been promoted vigorously as the causal agent of the Balkan endemic nephropathy because of similarities to some other nephropathies, association with DNA adducts and a perception of human exposure via bread. Critical evaluation of the literature exposes flaws in these aspects, and there has been consistent failure of experimental toxicology to mimic either the slow silent bilateral atrophy of the Balkan disease or the transitional cell carcinomas in the upper urothelium. It seems yet premature to promote the curious Balkan disease as aristolochic acid nephropathy without the epidemiological rigour necessary in biomedical research.
\end{abstract}

Keywords: DNA adducts; ethnobotanical exposure; Koch's postulates; pre-neoplastic lesion; transitional cell carcinoma

Received: 17 February 2016; Accepted after revision: 14 March 2016; Published: 29 March 2016.

Author for correspondence: Prof. Peter Mantle, Centre for Environmental Policy, Imperial College London, South Kensington, London, SW7 2AZ, UK. Email: p.mantle@imperial.ac.uk

How to cite: Mantle P, Herman D, Tatu C. Is Aristolochic Acid Really the Cause of the Balkan Endemic Nephropathy? J Controversies Biomed Res 2016; 2(1):9-20. Doi: http://dx.doi.org/10.15586/jcbmr.2016.14

Copyright: The Authors.

License: This open access article is licensed under Creative Commons Attribution 4.0 International (CC BY 4.0). http://creativecommons.org/licenses/by/4.0/

\section{Introduction}

Resolution of idiopathy in human disease has challenged physicians and research scientists since Robert Koch (1) defined experimental rigour for attributing microbial aetiological agents to the important plagues of tuberculosis, cholera and anthrax. Koch's postulates apply equally in plant pathology and, with suitable paraphrasing, in toxicology. Re-emphasis of the continuing need for rigour across diagnostic medical practice in general has been marked by the
Royal Society of Medicine by re-publishing the seminal paper by Hill (2) recently in its journal (3).

The curious syndrome of Balkan endemic nephropathy (BEN) has commanded much thought, study, conjecture, experiment and controversy since its recognition in the mid-1950s. Restricted location within parts of Bulgaria, Yugoslavia and Romania represented marked geo-political isolation 


\section{Key points}

- Balkan endemic nephropathy (BEN) and associated cancer is a unique entity.

- Equating BEN with Aristolochia poisoning needs proof of exposure and mimicry.

- Aristolochia exposure calculation for BEN homes is erroneous and contradicted.

- Balkan ethnobotanical use of Aristolochia clematitis infusions is not focal in BEN homes.

- Lifetime aristolochic acid/DNA adducts in tumour do not prove carcinogenesis.

- Mimicking the silent renal atrophy and urothelial cancer in animals is elusive.

that spanned isolation from Western Europe through the latter half of the century and the regional disturbances of the Yugoslav wars of the 1990s. It was even forbidden to admit to its occurrence in Romania in the Ceausescu era, whereas in Bulgaria the inhabitants of an endemic village (Karash) were relocated to a nonendemic area close to Sofia, in an attempt to cover up the problem. However, following a visit to the hyperendemic village of Erghevitza, the disease was publicised (4) and putative aetiology was discussed, including a passing consideration of Aristolochia (Birthwort). This arable weed plant, Aristolochia clematitis, is endemic in many parts of Eastern Europe and was known to be toxic to horses (5). Since 1961, food spoilage moulds (6) had become recognised as sources of some potent environmental toxicants, Barnes and Austwick (7) at the Medical Research Council Toxicology Unit in UK researched the focal nephrotoxicity of common Balkan Penicillium moulds isolated from a Romanian nephropathy village. Concurrently, Krogh (8) in Denmark was experimentally attributing the new mycotoxin ochratoxin A, originally sourced from a South African Aspergillus, as causing the chronic nephropathy plaguing the Danish bacon industry in the 1970s although the Danish source of ochratoxin A was yet another Penicillium mould. Through plausible aetiological extrapolation to the chronic Balkan renal disease (9), ochratoxin A became a major focus of research concerning nephropathy in pigs and poultry and became a concern as potentially being a risk factor for human nephropathy. General food-safety concerns escalated when the 1989 National Toxicology Program report showed this toxin to be the most potent renal carcinogen for the male rat (10). However, there was then no established case of acute or chronic human poisoning with ochratoxin A, and this situation persists. Meanwhile in Western Europe, a local epidemic of 'Chinese herbs nephropathy' in Belgian women in the 1990s, also in some cases leading to urothelial cancer, was attributed to a formulation error in a Chinese herbal slimming medication involving accidental inclusion of Asian material in which aristolochic acids (AA) were the characteristic alkaloid (11). However, Aristolochia spp. have long formed a part of the oriental Materia Medica in herbal formulations (12), and the general toxicity and carcinogenicity of AA were already well established in animals $(13,14)$ and occasionally in the orient. From initial consideration of AA's putative involvement in BEN, a considerable research literature is now asserting that the Belgian nephropathy and BEN are both AA nephropathy (15). It is time to make objective evaluation of that bio-medical literature; we do it from quite long personal experience and because of continuing need for evidence-base in epidemiology (16).

Experimental attempts to mimic the Belgian 'Chinese herbs nephropathy'

Early attempts to find an experimental animal model for the Belgian disease used female rabbits (17). Daily intraperitoneal delivery of a mixture of AAs I and II (0.1 $\mathrm{mg} / \mathrm{kg}$ b.w., ratio: 44:56 and determined as non-lethal) to 12 animals for up to or nearly 2 years caused marked glucosuria and proteinuria, extensive renal tubular atrophy and interstitial fibrosis in a context of reduced feed intake and poor concomitant growth. One rabbit died, but three developed urinary tract tumours (one in situ renal cell carcinoma in two outermedullary nephrons, one tubulopapillary adenoma $(5 \times 13 \mathrm{~mm})$ and one high-grade transitional cell carcinoma in mid-ureter together with an extensive peritoneal 
papillary malignant mesothelioma invading the submesothelium). Concerning the latter, and in view of earlier findings (13, 14) of stomach tumours in response to gavage administration of a high dose of AA to rats, repeated intraperitoneal administration to the rabbits may have first caused the mesothelioma from which the ureter tumour was a metastasis. Discrimination between the latter two neoplasms by immunohistochemistry had not been done; if archived tissues still exist, this could resolve the interrelationship. All the rabbit pathology above had arisen from a dosage regimen six times greater than that estimated for the human intake leading to Chinese herbs nephropathy. Notably, a gavage administration of much higher dose in rats (10 mg/kg b.w.) 5 days per week for 3 months had previously (18) caused no nephropathy, but significant squamous cell tumours were observed at the point of delivery (forestomach) 3 months later. A 60-fold lower dose (0.15 mg/kg b.w.), mimicking the rate implicit in the Belgian women's slimming regimen, led to one or two stomach tumours. Therefore, neither rat nor rabbit seems to be a perfect model here, at least for urothelial tumours. Nevertheless, the rabbit experiment was judged to support a causal role alone for $\mathrm{AA}$ in the Belgian disease. However, daily intraperitoneal injection, although experimentally convenient, is hardly desirable ethically or scientifically to mimic oral/dietary exposure.

Further aetiological application of experimental rabbit study to BEN is difficult because of the even greater disparity between the dosage used (17) and the mis-calculated estimate of the amount Balkan nephropathy subjects' exposure to A. clematitis seeds in bread (19) if exposure was to match that in Asian contexts where some herbal medicines contain AA.

\section{Experimental AA exposure towards mimicking BEN and/or urothelial tumours}

The slow bilateral renal atrophy of BEN and the development of urothelial tumours often appear to be concurrent processes, but the former probably arises first. A common cause is assumed in Chinese herbs nephropathy, though not universally accepted (20), but there is increasing recognition that chronic kidney disease itself may be a risk factor for cancer (21). Thus, it is prudent to keep an open mind concerning 'association' (22) between the renal atrophy and the cancer in the renal pelvis or upper ureter, whether directly caused by a single toxic entity common to all BEN cases or multifactorial or regionally distinctive. In this context, we refer to our metabolomic findings (23) that illustrated significant difference between BEN cohorts in the Vratza region of Bulgaria and the Dobreta Turnu Severin region in Romania, but not between control groups.

Seriousness of outcome during the Belgian epidemic, extending also to a few cases in UK involving both renal disease and urinary tract cancer, presented a scenario that had interesting parallel with BEN, except for the relatively much longer timespan in the latter. Nevertheless, although it could be desirable to mimic the slow silent bilateral renal atrophy of BEN, preferably with the characteristic general preservation of glomerular structure until a late stage of disease, this would be huge experimental challenge. There had been no US National Toxicology Programme study on AA to provide guidance, and this is still the case. Therefore, short-term animal experiments, expected to reveal obvious outcomes such as tumourigenesis, have been made.

First experiment addressing the mysterious aetiology of the BEN was made by Ivic (24). Occasionally, this seminal work is cited (25), but there are several exceptions (11, $20,26)$ and particularly the recent International Agency for Research on Cancer (IARC) monograph (27). The full article of the Ivic is very difficult to source, which may account, for example, for De Broe (28) also not mentioning the notable rat experiment that appears since not to have been included in considering a putative role of AA in BEN. Ten albino rats had been given injections of an aqueous percolate of A. clematitis seeds. Unfortunately neither the percolation method, quantitative dose, frequency (single or daily) of administration, nor any description of route (intraperitoneal or subcutaneous) and anatomical site(s) is given. However, rapidly growing polymorphocellular sarcomas became 
evident in all rats at injection sites within 3 months; these were the only tumours found. Ivic also describes an experiment with rabbits, given powdered $A$. clematitis seeds per os at a minimum daily dose of 20 mg powder $/ \mathrm{kg} \mathrm{b.w.} \mathrm{for} \mathrm{up} \mathrm{to} 14$ months. Within a month, proteinuria became evident and renal histology already showed changes in peripheral sub-capsular tubules together with some tubular epithelial repair and 'enormous nuclei'. Thereafter, histopathological changes progressed, whereas the kidney surface became corrugated, but no renal tumours were seen. All these pathologies were probably due to AA although contrary to a statement (22) that Ivic found AA in wheat flour, the original publication refers only to the plant seeds because alkaloid analysis was not available. It is however possible to estimate a daily AA intake by applying a $6.5 \mathrm{mg} / \mathrm{g}$ value for $A$. clematitis seeds (19). This translates to $130 \mu \mathrm{g} \mathrm{AA} / \mathrm{kg}$ b.w., of an order similar to that used in the study of Cosyns et al (17), also in the rabbit. Nevertheless, no urothelial tumours occurred.

The only experiment to yield significant proliferative nephropathy is that Cui et al (25) who gave AA I to 14 female Sprague Dawley rats for 3 days (total dose 150 $\mathrm{mg} / \mathrm{kg}$ b.w.). Rats were sluggish and anorexic for a week. Six months later, proliferations within renal tissue (unilateral or bilateral), designated by the authors as pre-neoplastic lesions, occurred in $13 / 14$ rats in the form of nodules, the smallest of which were already 2-3 $\mathrm{mm}$ in diameter, whereas larger ones extended through the capsule. Four unilateral renal tumours occurred, designated as an oncocytoma, and three mesenchymal tumours, but notably, there were no transitional cell tumours in urothelia. Consequently, the experiment could not support a tumourigenic activity that modelled the transitional cell carcinomas associated with BEN, even after a large acute insult from AA I. Nevertheless, the range of renal neoplastic proliferations in these rats was striking. Their extent of genetic change might have been revealed by comparing measurement of DNA ploidy distribution in these kidneys with the marked aneuploidy found in rat renal tumours arising from chronic dietary exposure to ochratoxin A (29), but this could not be arranged.

Pharmacokinetic study of the AAcontaining Chinese herb medication Radix Aristolochiae in beagle dogs $(5-6 \mathrm{Kg})$ involved either a single intragastric administration or daily doses for up to 6 months (30). Dosage of the AA component on a body weight basis was not defined, but may be implied from the study of BaoPing et al (31) as $2.5 \mathrm{mg} / \mathrm{kg}$ b.w.. After a single (fasted) dose, the short plasma halflife was not more than one hour. During the chronic dosing study, there were several unscheduled deaths and significant renal histopathological changes occurred, as expected from doses in the $\mathrm{mg} / \mathrm{kg} \mathrm{b.w}$. range. After one month's dosing, no toxin was detectable in plasma, although by 3 or 6 months, a value of $\sim 0.3 \mu \mathrm{g} / \mathrm{ml}$ was recorded. A month after dosing had ceased, no AA was detected in plasma. Because canines are often used for chronic toxicity tests in humans, the tendency of AA not to accumulate in vivo, even during high daily dose, raises questions about the pharmacokinetics of small occasional human exposures, especially with a very short plasma half-life. In any case, it would be interesting, relative to findings in our recent rat study (32), whether immunohistochemistry could similarly reveal cryptic pre-neoplastic renal lesions in the canines above (30) studied after 6month exposure to intragastric AA. Presumably, authors of the canine study may still have wax blocks of the kidneys.

\section{AA/DNA adducts}

Schmeiser et al (33) extended earlier toxicological works $(13,14)$, by demonstrating DNA adducts in organs of Wistar rats after five doses of AA I or AA II (as sodium salt, $10 \mathrm{mg} / \mathrm{kg} /$ day by gavage). Adducts were found, for example, both in forestomach, where AA-derived tumours can occur, and in liver where they do not occur, though unfortunately blood was not analysed. Only AA II produces adducts in bladder, where some extension of ureter transitional cell epithelium occurs. Notably, authors perceived no direct correlation between adduct formation and carcinogenesis. Further research (34) followed the same dosing regimen with AA I 
to 40 male Wistar rats 5 days a week for 12 weeks. Thereafter over 15 weeks, papillomatosis was evident in the stomach of all decedent or euthanized animals, and squamous cell carcinomas were evident in 18 animals in forestomach alone, in ear duct alone (normally very rare) or together. Additionally, $58 \%$ of rats developed adenocarcinomas or sarcomas in the small intestine. In one rat, with squamous cell carcinoma in the stomach and a small carcinoma in intestine, adenocarcinoma also occurred in kidney, but was not further attributed either as a primary tumour or as a metastasis. Clearly, that treatment had been highly carcinogenic in response to a large cumulative dose $(\sim 600$ $\mathrm{mg} / \mathrm{kg} \mathrm{b.w.).} \mathrm{Nevertheless,} \mathrm{there} \mathrm{were} \mathrm{no}$ urothelial tumours.

In the context of the Belgian nephropathy, Cosyns et al (11) cite that AA feeding in the rat generates apparently lifelong AA/DNA adducts (35). The abstract of the latter study states that a $13.8-\mathrm{mmol}$ AA dose $(4.7$ g, presumably an error) generated renal adducts for up to 36 weeks. Further, in the study of Fernando et al (35), it is cited (36) that six presumably morbid kidneys removed from Belgian Chinese herbs nephropathy patients had AA/DNA adducts up to 44 months after the end of the contaminated herbs consumption. Concurrently reported, an approximately 1mg oral dose of AA I sodium salt had been given to male Wistar rats (200-240 g); AA/DNA adducts were detected in kidneys up to 36 weeks later in spite of notable quantitative decay during the first month. Thus, a similar residual adduct situation probably prevailed in the study of Cui et al (25). However, lifelong adduct persistence in adult rats (11) has not been confirmed experimentally; the data had been obtained after a moderately large acute oral dose of AA $(5 \mathrm{mg} / \mathrm{kg}$ b.w.). Other literature indicates that AA has a very short plasma half-life (30).

Recent finding of DNA adducts in kidneys of several Belgian cases of AA nephropathy more than 20 years after the original adulterated Chinese herbs exposure had ceased to be remarkable (37). However, just finding the biomarker in human tissues is an imprecise indicator of when exposure may have occurred, and also whether the pattern observed could have been generated during a long period of occasional exposure. It is not known whether 'old' adducts retain the capacity to yield a mutation through mis-repair, but if so, it would be important to know the distribution of adducts across organs and tissues and how that fits with where tumours arise. We have no problem with the formation of AA/DNA adducts in vivo after ingestion of AA, one of us having produced them in rat kidney for an EC project, but apparent omission to analyse non-renal tissues in most publications on AA toxicity reflects poor design. Adducts can persist for up to 9 months also in rat kidney after a single, quite large, $5 \mathrm{mg} / \mathrm{kg}$ b.w. dose (38), but more helpful data after low-dose chronic exposure are unfortunately lacking.

Several recent publications have tabulated AA-DNA adducts in tissues of Belgian 'Chinese herbs nephropathy' patients, BEN urothelial tissues and more widely in animal studies (39-42). Surprisingly, no adduct analysis of blood seems to have been made, even where blood samples have been taken $(42,43)$, ignoring the intimate opportunity for access of toxin to nucleate leucocytes. An analogous situation has prevailed concerning OTA for many years although the presence of DNA adducts in blood has recently been reported (44). Consequently, for AA-DNA adducts, there remains general uncertainty about reported quantitative measurements in vascularised tissues. A very recent publication (45) reports enhanced AA-DNA adduct formation by OTA in rats, with indirect implication for ideas about OTA in BEN tumourigenesis. This had already been recognised generically (46) for OTA on account of common complex aneuploidy in rat renal/OTA tumours and Romanian BEN urothelial tumours. However, it is important to remember that, although mis-repair of adducts can be a route to cancer, occurrence only indicates exposure, and exposure is an important dimension of satisfying Koch's postulates in epidemiology.

\section{Natural exposure to AAs for residents of BEN villages}

Attribution of historic AA exposure of BEN patients to AA to contaminated bread (19) 
has already been discussed critically (23), and we illustrated occurrence of $A$. clematitis in the Romanian village of Erghevitza, which is historically notable as hyperendemic for BEN, and described some local ethnobotanical usage of leaves of the plant in preparations for both internal and external use. However, a question arises whether it is plausible that prospective BEN patients in certain households in specific Balkan villages had been consuming bread each day made from a wheat flour component containing, for each person, approximately seven mature seeds (150 mg) of $A$. clematitis, during at least the past seven decades, whereas other neighbours in mosaic format have not. Because there are diametrically opposing publications concerning $A$. clematitis contamination of wheat in Croatia $(19,47)$, it is regrettable that this matter has not been resolved since it arose from the same city. At least it seems that the weed does not usually produce ripe seed at the time of wheat harvest. Even if a second generation of blooming and seed formation in $A$. clematitis occurs during the year, this usually takes place in September, long after the wheat harvesting season. It is unfortunate that medical epidemiology has not thought laterally and agriculturally in this topic. Thus, it is astonishing that in the past decade, so much medical and scientific opinion accepts a deduction, that is without any factual quantitative basis. The seven-fold mis-calculation factor (19) of hypothetical intake of AA in bread in BEN households via 'co-mingling of seed with wheat' is of the same order as the rat lifetime dose range for ochratoxin A (OTA) to cause either a high incidence of renal tumours or none $(10,48)$. This is a significant dose/response relationship. Not just one (as proposed, 19) but seven mature seeds would need to have been in the daily bread intake of a particular person in a hyperendemic BEN village, and still the error is perpetuated (49). Simple independent agricultural survey in hyperendemic BEN villages across the Balkans could easily reveal the natural growth dynamics between wheat and its $A$. clematitis weed. Concurrent measurement of AA biosynthesis in fruits of all stages between and within the branching plants will easily show a real relationship between a value of $0.65 \%$ AA in ripe seed (19) and the value in seed within $A$. clematitis plants that might occur at wheat harvest. Even published illustration shows temporal disconnect between a ripe wheat crop and green immature A. clematitis (50). Already, Ivic had recorded (24) that in the 1960s, $A$. clematitis was common as an agricultural weed in some wheat fields near a nephropathic area in what is now Southern Serbia. In contrast, the weed was mainly restricted to field edges, roadsides and barren land surrounding the highly nutritious soils of the Voivodina located north-west of Belgrade, at the latitude, topography and elevation in which are there other hyperendemic BEN hotspots. Ivic had never seen $A$. clematitis in the corn-fields of the Voivodina.

A very recent publication (51) raises a new question as to whether AA can cause renal cell carcinoma because AA adducts (exclusively dA-AL-I) were found in peritumoural cortex of patients in non-BEN Romanian counties receiving sparing surgery for renal cell carcinoma. Adducts were not found in comparable tissues from non-Balkan locations. Unfortunately, analogous experimental animal findings cannot be attributed to AA because no consistent analogous urological tumours have yet been caused. Claims for renal cell carcinoma causation are cautious, partly because no AA exposure via contaminated bread could reasonably be envisaged, although ethnobotanical sources might easily cause sufficient intake to generate persistent AA/DNA addicts. However, authors did not cite (25) as being the only description of experimental AA renal neoplasms although hardly mimicking renal cell carcinoma. They also omitted the rather obvious deduction that consistent traces of AA adducts in kidney cortex of non-BEN area residents of southern Romania disconnect the occurrence in BEN patients from having compelling diagnostic value for BEN tumour aetiology. Notably, AA has not caused renal carcinoma in the rat (33). Thus, the absence of a DNA adduct with dA-AL- II [lacking the methoxy substituent of AA I] (51) could be consistent with the perceived hypothetical relevance of dA-AL- I to renal cell carcinoma aetiology. However, AA I is a preferred toxin for modelling BEN in view of 
current popular focus on $A$. clematitis as its cause $(25,32)$.

\section{Attempt to mimic rat nephropathy findings of Cui et al (25)}

We have recently sought to repeat the general protocol of Cui et al (25) in strain and gender of seven rats, gavaged dose on a body weight basis, frequency and route of administration and duration thereafter, and subsequent study of pathology (32). In the study of Cui et al (25), AA1 (>95\% purity) had been isolated from Aristolochia manshuriensis Kom, predictably similar to the commercial AA1 we used (32). However, our rats were likely to have had only their first oestrus (52). They were therefore a little younger when dosed than rats in the study of Cui et al (25), but were retained a month longer to compensate, predictably even to improve finding tumours. Therefore, the absence of any gross neoplasms in that study, particularly in stomach and throughout the urinary tract, or of microscopic evidence of tumours in kidney sections stained with $\mathrm{H} \& \mathrm{E}$, are in spite of giving the quite large $\mathrm{AA}$ insult (cumulative semi-acute AA dose $150 \mathrm{mg} / \mathrm{kg}$ b.w.). Presumably, AA/DNA adducts could still have been detectable there; we had anticipated at least one renal tumour. However, immunohistochemical probing of renal sections for p-S6 ribosomal protein (42) revealed proliferation in a proximal tubule closely matching the morphology of a classical pre-neoplastic lesion (53) but quite different from the illustration as shown by Cui et al (25). It is of concern that corroboration of Cui et al (25) was not possible; also our concept of a preneoplastic lesion is very different. The preneoplastic proliferation is also reminiscent of the periphery of a matching small neoplastic lesion in a rat given protracted exposure to dietary OTA (Figure 2A in 54). Extensive serial sectioning and immunohistochemical staining for S6 protein in our present AA rat kidneys might have revealed other examples if resources had been available.

Female Sprague Dawley rats were also exposed continuously to infusion of $A$. clematitis leaves as drinking water for 6 months without any clinical effect or renal histopathology (42). The cumulative dose was several times greater than the acute dose given in the study of Cui et al (25). Although only on a pilot scale, tolerance of AA in drinking water (nearly $1 \mathrm{mg}$ daily) hardly encourages expectation of health risk to humans of Balkan ethnobotanicalscale exposure. Nevertheless, tumour absence might represent a low-dose part of a thresholded dose/tumour incidence curve, based on log dose/response relationships for chemical carcinogens for which nephrocarcinogenic OTA is the perfect model (55), albeit via chronic exposure. Of course, there is yet no experimental basis for this concerning AA. In the context of thresholded carcinogenesis, Kuiper-Goodman et al (56, Figure 1) illustrate National Toxicology Program rat renal cancer data for OTA (10) that at first sight matches the principle elaborated in the study of Waddell (55). However, the graphical plot is extrapolated awkwardly to zero as if the carcinogenic principle was not thresholded, unfortunately failing to cite issues raised in the study of Waddell (55). Such literature might adversely influence expectations concerning AA in competing attitudes to the two carcinogens OTA and AA as aetiological candidates for BEN tumourigenesis. In further development of the threshold principle (55), it was concluded that a logarithmic function for adducts does not predict a threshold for adduct formation; functionally, a threshold is crossed when pre-neoplastic foci appear. Further, adducts may be present without any progression to pre-neoplastic foci, and pre-neoplastic foci may be present without progression to tumours. Until firm experimental data become available, such as through a lifetime exposure toxicology study, it may be wise to regard $\mathrm{AA}$ as conforming to the principle in the study of Waddell (55). Hence, assuming that the urothelial carcinogen in BEN is $\mathrm{AA}$, even when verified quantitative exposure is uncorroborated and may be vanishingly small, is as unsound for clinical medicine as is the selective use of literature in the scientific work.

The present diagnosis of a pre-neoplastic lesion in the outer medulla 7 months after AA exposure ceased raises the question of whether DNA adducts had persisted there instead of in the transitional cell lining of 
the renal pelvis, to model a human BEN tumourigenesis. Of course, adducts may be everywhere in a body, and more comprehensive study is required. Further, it is important not to be mis-led by the IARC monograph (27) concerning rat tumours in the renal pelvis because we are unable to find verification of this in the cited literature $(13,14,18,34,57)$. Further, finding AA-DNA adducts in renal cortex of only $70 \%$ of BEN cases [56\% in males, $80 \%$ in females] (42) hardly justifies the claim that AA is the cause of both the bilateral renal atrophy and any urological tumour found during nephroureterectomy in BEN patients. Koch's postulates would not have been satisfied. In any case, human renal pelvis tumours should have been analysed for DNA adducts, considering that tubular epithelium in renal cortex is not a conventional site for $\mathrm{BEN}$-associated renal tumours. Association is a dangerous word in epidemiology.

It is notable that in the Belgian nephropathy, an average cumulative AA intake was of the order of $0.6 \mathrm{~g}$ over about 20 months, after which it was 2-6 years before urothelial malignancy was discovered in some women. In contrast, even the full development of renal failure after BEN diagnosis may take 15-20 years. Because only after a fatal accident might early transitional cell proliferation in urothelia be recognised in a 'potential' BEN patient, its place in the BEN syndrome dynamics is unclear and the temporal duration of tumourigenesis is unknown although probably it can be measured in years. In any case, the present intense focal over-expression in rats of $\mathrm{p}-\mathrm{S} 6$ ribosomal protein in a key urological site for tumourigenesis provides perhaps for the first time a biomarker of AA-induced malignancy other than near-administration sites associated with severe local toxicosis. The latter may be regarded as an artefact of high-dose experimentation, but attempts to translate directly to BEN circumstances might require completely unreasonable quantitative exposure to AA.

We are not yet aware of genome data on any other urological cancer of plant or fungal toxin origin, such as the abundant rat renal tumours from OTA (10), with which to verify a unique diagnostic signature claimed (58,
59) for $\mathrm{AA}$ in BEN tumours. It is unfortunate that other tumours in BEN cases, e.g. in lung caused by tobacco smoke, seem not yet to have been studied. For example, would that mutational signature in a lung tumour implicate AA as the cause, as tentatively perceived for renal cell carcinoma (51)? Would that transformation represent the initial genome error in a pre-neoplastic lesion, or part of the progression of changes during tumour growth? A more comprehensive study of human tumourigenesis in Balkan nephropathy hyperendemic foci is needed concerning risks from AA exposure from whatever firmly measured source. The present uncertainties do not help in predicting that AA causes the urothelial tumours in BEN patients, even if this was so in the Belgian herbs cases with high and protracted AA intake. This is particularly so because evidence of focal dietary AA exposure in BEN hyperendemic villages is unreliable and the intake via ethnobotanical practices is probably only on a homeopathic scale and also occurs in geographically unrestricted, beyond the boundaries of the BEN areas.

\section{Conclusions}

Disconnect between putative animal models and human urothelial susceptibility to AA tumourigenesis may of course be an inescapable natural barrier in experimentation. Indeed, the alarm caused over 20 years ago by the discovery of OTA as the most potent renal carcinogen in the male rat (10), with the potential commercial impact on pig kidney, cereals, beer, coffee and red wine as risk commodities for human urological disease, is hardly justified with hindsight. There is no clearly documented case of human ochratoxicosis, and no case of experimental transitional cell carcinoma from OTA in an animal model that might link it with BEN. Notably, it is important not to be confused by transitional cell hyperplasia, a non-neoplastic and nonmetastasising proliferation within the renal pelvis, illustrated for chronic rat ochratoxicosis in a classic renal toxicology text (Figure 11 in 60) although not sourced from the cited reference (10).

Consequently, we are not yet persuaded that AAs caused and continue to cause 
BEN, because uncertainty abounds in satisfying rigorous epidemiological criteria concerning exposure to the toxin, interpretation of DNA adduct findings, specificity of a molecular signature and all the work with putative animal models. BEN deserves thoughtful, objective, rigorous and even humble approach to its epidemiology.

\section{Conflicts of Interest}

The authors declare no conflict of interest.

\section{References}

1. Koch R. Untersuchungen über Bakterien: V. Die Ätiologie der MilzbrandKrankheit, begründet auf die Entwicklungsgeschichte des Bacillus anthracis. Cohns Beitrage zur Biologie der Pflanzen 1876;2:277-310.

2. Hill AB. The environment and disease: Association or causation? 1965. J R Soc Med. 2015;108:32-37.

http://dx.doi.org/10.1177/014107681456 2718.

3. Wakeford R. Association and causation in epidemiology - half a century since the publication of Bradford Hill's interpretational guidance. J R Soc Med. 2015;108:4-6.

http://dx.doi.org/ 10.1177/014107681456 $\underline{2713}$.

4. Austwick PK. Balkan nephropathy. Practitioner. 1981;225:1031-1038.

5. Martincic M. Toxische einwirkungen der Aristolochia clematitis auf die Niere des Pferdes. Vet Arhiv 1958;27: 51-59.

6. Lancaster MC, Jenkins FP, Philip JM. Toxicity associated with certain samples of groundnuts. Nature (London) 1961;192:1095.

7. Barnes JM, Austwick PK, Carter RL, Flynn FV, Peristianis GC, Aldridge WM. Balkan (endemic) nephropathy and a toxinproducing strain of Penicillium verrucosum var cyclopium: An experimental model in rats. Lancet 1977;1:671-675.

8. Krogh P. Causal associations of mycotoxic nephropathy. Acta Pathol
Microbiol Scand Sect A Suppl 1978;269: $1-28$.

9. Krogh P. Mycotoxic porcine nephropathy - a possible model for Balkan (endemic) nephropathy. In: Puchlev A, Dinev V, Milev B, Doichinov D, editors, Endemic nephropathy. Sofia: Bulgarian Academy of Sciences; 1974. p. 266.

10. Boorman GA. Toxicology and carcinogenesis studies of ochratoxin A. NIH Publication No 89-2813. Research Triangle Park, NC: National Toxicology Program; 1989.

11. Cosyns JP, Jadoul M, Squifflet JP, Wese FX, van Ypersele de Strihou C. Urothelial lesions in Chinese-herb nephropathy. Am J Kidney Dis. 1999;33:1011-1017.

http://dx.doi.org/10.1016/S02726386(99)70136-8.

12. NTP. Report on carcinogens; background document for aristolochic acid. 2008

(http://ntp.niehs.nih.gov/files/aristolochic acids_(final-02sep08)_redo2\%5B3\%5D .pdf) accessed 5 February 2016.

13. Mengs U, Lang W, Poch JA. The carcinogenic action of aristolochic acid in rats. Arch Toxicol 1982;51:107-119.

14. Mengs U. On the histopathogenesis of rat forestomach carcinoma caused by aristolochic acid. Arch Toxicol. 1983;52:209-220.

15. Grollman AP. Process of elimination. The New Yorker 2013 September;15:5.

16. Alexander CE, Dahm P, Omar MI. What is the role of evidence-based medicine in urology? Urology News 2016;20:6-10.

17. Cosyns JP, Dehoux JP, Guiot Y, Goebbels RM, Robert A, Bernard AM, et al. Chronic aristolochic acid toxicity in rabbits: A model of Chinese herbs nephropathy? Kidney Int. 2001;59:2164-2173.

http://dx.doi.org/10.1046/j.1523-

1755.2001.00731.x.

18. Cosyns JP, Goebbels RM, Liberton V, Schmeiser HH, Bieler CA, Bernard AM. 
Chinese herbs nephropathy-associated slimming regimen induces tumours in the forestomach but no interstitial nephropathy in rats. Arch Toxicol. 1998;72:738-743.

19. Hranjec T, Kovac A, Kos J, Mao W, Chen JJ, Grollman AP, Jelakovic B. Endemic nephropathy: The case for chronic poisoning by Aristolochia. Croat Med J 2005;46:116-125.

20. Pfohl-Leszkowicz A. Ochratoxin A and aristolochic acid involvement in nephropathies and associated urothelial tract tumours. Arh Hig Rada Toksikol. 2009;60:465-483.

http://dx.doi.org/10.2478/10004-125460-2009-2000.

21. Stengel B. Chronic kidney disease and cancer: A troubling connection. J Nephrol. 2010;23:253-262.

22. Stefanovic V, Toncheva D, Atanasova S, Polenakovic M. Etiology of Balkan endemic nephropathy and associated urothelial cancer. Am J Nephrol. 2006;26:1-11.

http://dx.doi.org/10.1159/000090705.

23. Mantle P, Modalca M, Nicholls A, Tatu C, Tatu D, Toncheva D. Comparative (1) H NMR metabolomic urinalysis of people diagnosed with Balkan endemic nephropathy, and healthy subjects, in Romania and Bulgaria: A pilot study. Toxins (Basel). 2011;3:815-833.

http://dx.doi.org/10.3390/toxins3070815.

24. Ivic M. The problem of aetiology of endemic nephropathy. Acta Facultatis medicae Naissensis 1970;1:29-38.

25. Cui M, Liu ZH, Qiu Q, Li H, Li LS. Tumour induction in rats following exposure to short-term high dose aristolochic acid I. Mutagenesis. 2005;20:45-49.

http://dx.doi.org/10.1093/mutage/gei00.

26. Gökmen MR, Cosyns JP, Arlt VM, Stiborová M, Phillips DH, Schmeiser HH, et al. The epidemiology, diagnosis, and management of aristolochic acid nephropathy: A narrative review. Ann Intern Med. 2013;158:469-477. http://dx.doi.org/10.7326/0003-4819-

158-6-201303190-00006.

27. Tong SGM. Plants containing aristolochic acid.

http://monographs.iarc.fr/ENG/Monograp hs/vol100A-23.pdf 2012 accessed 5 February 2016.

28. De Broe ME. Chinese herbs nephropathy and Balkan endemic nephropathy: Toward a single entity, aristolochic acid nephropathy. Kidney Int. 2012;81:513-515.

http://dx.doi.org/10.1038/ki.2011.428.

29. Brown AL, Odell EW, Mantle PG. DNA ploidy distribution in renal tumours induced in male rats by dietary ochratoxin A. Exp Toxicol Pathol. 2007;59:85-95. http://dx.doi.org/10.1016/j.etp.2007.05.0 $\underline{01}$.

30. Yang HY, Zheng XH, Du Y, Chen Z, Zhu DY, Lou YJ. Kinetics of aristolochic acid I after oral administration of Radix Aristolochiae or Guanxinsuhe preparation in canines. J Ethnopharmacol. 2011;135:569-574.

http://dx.doi.org/10.1016/j.jep.2011.03.0 $\underline{54}$.

31. Bao-Ping $\mathrm{T}$, Lan-tong $Z$, Zhi-Fang $\mathrm{Y}$, Wei-na L, Hong-Ju L. Pharmacokinetics of aristolochic acid A in Radix Aristolochiae and Guanxinsuhe capsule. Chinese Traditional and Herbal Drugs 2005;36:1671-1674.

32. Gruia A, Gazinska P, Herman D, Ordodi V, Tatu C, Mantle P Revealing a pre-neoplastic renal tubular lesion by $\mathrm{p}-\mathrm{S} 6$ protein immunohistochemistry after rat exposure to aristolochic acid. J Kidney Cancer VHL 2015;2:153-162.

33. Schmeiser HH, Schoepe KB, Wiessler M. DNA adduct formation of aristolochic acid I and II in vitro and in vivo. Carcinogenesis. 1988;9:297-303.

34. Schmeiser HH, Janssen JW, Lyons J, Scherf HR, Pfau W, Buchmann A, et al. Aristolochic acid activates ras genes in rat tumors at deoxyadenosine residues. Cancer Res. 1990;50:5464-5469. 
35. Fernando RC, Schmeiser HH, Scherf HR, Wiessler M. Formation and persistence of specific purine DNA adducts by 32Ppostlabelling in target and non target organs of rats treated with aristolochic acid 1. In: Phillips DH, Castegnaro M, Bartsch $\mathrm{H}$, editors. Postlabelling methods for detection of DNA adducts. Lyon, France: International Agency for Research on Cancer; 1993, p. 167-171.

36. Bieler CA, Stiborova M, Wiessler M, Cosyns JP, van Ypersele de Strihou C, Schmeiser HH. 32P-post-labelling analysis of DNA adducts formed by aristolochic acid in tissues from patients with Chinese herbs nephropathy.

Carcinogenesis. 1997;18:1063-1067.

37. Schmeiser $\mathrm{HH}$, Nortier JL, Singh $\mathrm{R}$, Gamboa da Costa G, Sennesael J, CassutoViguier E, et al. Exceptionally long-term persistence of DNA adducts formed by carcinogenic aristolochic acid I in renal tissue from patients with aristolochic acid nephropathy. Int J Cancer. 2014;135:502507.

38. Pfohl-Leszkowicz A. Formation, persistence and significance of DNA adduct formation in relation to some pollutants from a broad perspective. Adv Mol Toxicol 2008;2:183-240.

39. Chan W, Yue H, Poon WT, Chan YW, Schmitz OJ, Kwong DW, et al. Quantification of aristolochic acid-derived DNA adducts in rat kidney and liver by using liquid chromatography-electrospray ionization mass spectrometry. Mutat Res. 2008;646:17-24.

http://dx.doi.org/10.1016/j.mrfmmm.200 8.08.012.

40. Hao Y, Wan C, KongJie Y, Lin G, Ning L, HuWei L, ZongWei C. Recent progress in quantitative analysis of DNA adducts of nephrotoxin aristolochic acid. Science in China series B: Chemistry 2009;52:15761582 .

41. McDaniel LP, Elander ER, Guo X, Chen T, Arlt VM, Mei N. Mutagenicity and DNA adduct formation by aristolochic acid in the spleen of Big Blue ${ }^{\circledR}$ rats. Environ Mol Mutagen. 2012;53:358-368.

http://dx.doi.org/10.1002/em.21696.
42. Jelaković B, Karanović S, Vuković-Lela I, Miller F, Edwards KL, Nikolić J, et al. Aristolactam-DNA adducts are a biomarker of environmental exposure to aristolochic acid. Kidney Int. 2012;81:559-567.

http://dx.doi.org/10.1038/ki.2011.371.

43. Debelle F, Nortier J, Arlt VM, De Prez E, Vienne A, Salmon I, et al. Effects of dexfenfluramine on aristolochic acid nephrotoxicity in a rat model for Chineseherb nephropathy. Arch Toxicol. 2003;77:218-226.

http://dx.doi.org/10.1007/s00204-0030438-y.

44. Pfohl-Leszkowicz A, Faucet-Marquis V, Tozlovanu M, Peraica M, Stefanovic V, Manderville R. C8-2'-Deoxyguanosine ochratoxin A-adducts and OTA metabolites in biologic fluids as biomarkers of OTA exposure. In: Proceedings of MycoRed International Conference, Mendoza, Argentina, 15-17 November 2011; p. 90.

45. Stiborová M, Bárta F, Levová K, Hodek $\mathrm{P}$, Frei E, Arlt VM, et al. The influence of ochratoxin A on DNA adduct formation by the carcinogen aristolochic acid in rats. Arch Toxicol. 2015;89:2141-2158. http://dx.doi.org/10.1007/s00204-0141360-1.

46. Mantle PG, Amerasinghe C, Brown AL, Herman D, Horn T, Krogh T, et al. A pilot study of nuclear instability in archived renal and upper urinary tract tumours with putative ochratoxin aetiology. Toxins (Basel). 2010;2:326-340.

http://dx.doi.org/10.3390/toxins2030326.

47. Pepeljnjiak S, Klaric MS. Suspects in etiology of endemic nephropathy: Aristolochic acid versus mycotoxins. Toxins 2010;2:1414-1427.

48. Mantle PG. Minimum tolerable exposure period and maximum threshold dietary intake of ochratoxin A for causing renal cancer in male Dark Agouti rats. Food Chem Toxicol. 2009;47:2419-2424. http://dx.doi.org/10.1016/j.fct.2009.05.0 43.

49. Jelaković B, Nikolić J, Radovanović $Z$, Nortier J, Cosyns JP, Grollman AP, et al. Consensus statement on screening, 
diagnosis, classification and treatment of endemic (Balkan) nephropathy. Nephrol Dial Transplant. 2014;29:2020-2027. http://dx.doi.org/10.1093/ndt/gft384.

50. Debelle FD, Vanherweghem J-L, Nortier JL. Aristolochic acid nephropathy: A worldwide problem 200. Kidney Int 2008;74:158-169.

51. Turesky RJ, Yun BH, Brennan $P$, Mates D, Jinga V, Harnden P, Banks RE, Blabche $\mathrm{H}$, Bihoreau M-T, Chopard $\mathrm{P}$, Letourneau L, Lathrop GM, Scelo G, Aristolochic acid exposure in Romania and implications for renal cell carcinoma. Brit J Cancer 2015, http://dx.doi.org/10.1038/bjc.2015.402.

52. Evans AM. Age at puberty and first litter size in early and late paired rats. Biol Reprod. 1986;34:322-326.

53. Early Onset of Spontaneous Renal Preneoplastic and Neoplastic Lesions in Young Conventional Rats in Toxicity Studies. http://tpx.sagepub.com/content/35/4/58 9/F6.expansion.html accessed 5 February 2016.

54. Gazinska P, Herman D, Gillett C, Pinder S, Mantle P. Comparative immunohistochemical analysis of ochratoxin A tumourigenesis in rats and urinary tract carcinoma in humans; mechanistic significance of p-S6 ribosomal protein expression. Toxins (Basel). 2012;4:643-662. http://dx.doi.org/10.3390/toxins4090643.

55. Waddell WJ. Critique of dose response in carcinogenesis. Hum Exp Toxicol. 2006;25:413-436.
56. Kuiper-Goodman T, Hilts C, Billiard SM, Kiparissis Y, Richard IDK, Hayward S. Health risk assessment of ochratoxin A for all age-sex strata in a market economy. Food Add Contam: Part A 2010;27:212240.

57. Hadjiolov D, Fernando RC, Schmeiser HH, Wiessler M, Hadjiolov N, Pirajnov G. Effect of diallyl sulphide on aristolochic acid-induced forestomach carcinogenesis in rats. Carcinogenesis 1993;14:407-410.

58. Grollman AP, Shibutani S, Moriya M, Miller F, Wu L, Moll U, et al. Aristolochic acid and the etiology of endemic (Balkan) nephropathy. Proc Natl Acad Sci U S A. 2007;104:12129-12134.

http://dx.doi.org/10.1073/pnas.07012481 04.

59. Poon SL, Pang S-T, McPherson JR, Yu W, Huang KK, Guan P, et al. Genome-wide mutational signatures of aristolochic acid and its application as a screening tool. Sci. Transl. Med. 2013;5:197.

60. Dietrich DR, Svenberg JA. Renal carcinogenesis. Chapter 19. In: Hook JB, Goldstein RS, editors. Toxicology of the kidney. 2nd ed. New York, USA: Raven Press; 1993. p. 495-537.

(http:/ / books.google.co.uk/ books?id=61CA fmFDBrEC\&pg=PA505\&lpg=PA505\&dq=die trich+swen+renal+carcinogenesis+berg\&so urce $=$ bl\&ots $=$ HgLxhxlmn $1 \&$ sig $=1 \mathrm{LaaFZlEV}$ b8_4T80NxA6zknOcWY\&hl=en\&sa $=\mathrm{X} \& \mathrm{ei}=\mathrm{Q}$ 43gU5nuIKfH7Aa9gIEg\&ved=0CBYQ6AEw AA\#v=onepage\&q=dietrich\%20swen\%20ren al\%20carcinogenesis\%20berg\&f=false) accessed 3 February 2016. 